\title{
Method of vertical connection of steel bar and material requirements
}

\author{
Yan-Ting Hao ${ }^{1, a}$, Ming $\mathrm{Li}^{1, \mathrm{~b}, *}$ and Pei-Nan Zhang ${ }^{1, \mathrm{c}}$ \\ 1 Shenyang Jianzhu University, Shenyang, 110168, China. \\ ahao_yanting@163.com, bdingxianxing@126.com, cnimozhang@foxmail.com \\ ${ }^{*}$ Corresponding author
}

\begin{abstract}
Keywords: Assembly concrete, Steel bar, Connection mode, Sleeve connection
Abstract.With the advantages of short construction period, environmental protection and so on, the structure of assembly concrete has became the main direction of the development of architectural industrialization. Among them, the steel bar connection between the precast units is an important link of the force and construction of structure. And the research on this aspect is mainly from the angle of structure and construction. Therefore, this paper summarizes the methods and characteristics of the vertical bar connection in current cast-in-site and assembly concrete structure, including binding connection, welding connection, mechanical connection and sleeve grouting connection and etc.. It points out the problems and technical difficulties and hopes to research from the angle of material and better solve these problems. These reviews can provide reference for materials engineers in this field.
\end{abstract}

\section{Introduction}

Assembly concrete structure, a kind of concrete building structure, which is prefabricated in the factory and assembled on the construction site.In recent years, assembly concrete structure has been more and more concerned by engineers., with it's advantages, among which are high production efficiency, less wet operation, small environmental pollution and the like. In the assembly concrete structure, connected node between the precast units is an important part of the force and construction of structure .That is to say, the connection technology of assembly concrete structural members is a critical link to determine the reliability and applicability of the structure. Among them, the steel bar connection is a key of prefabricated connections and one of the key construction technology of prefabricated construction. The connection performance will directly affect the bearing capacity, stiffness and plastic deformation capacity of the whole structure. Therefore, civil engineers has focused on the research of connection form, construction methods. Mainly in the construction of professional researchers engaged in this area of research. If the research find a new kind of material to meet the demand of assembly concrete connection from the angle of the material, the technical difficulties in assembly concrete structure will probably be solved. For this reason, this article would review the form of steel bar connection in the present cast-in-site and assembly concrete structure. So as to provide a reference for the material engineers who engaged in the research of this aspect.

\section{Form of steel bar connection}

\section{The vertical connection form of the cast-in-site concrete structure}

The vertical bar connection of cast-in-site concrete structure is commonly used in connection with binding connection, welding connection and mechanical connection.

\section{Binding connection}

Binding connection (Fig.1) is a mode to transfer the stress of steel bar though bond force between steel bar and concrete. Due to the character of relatively reliable connection and easy to guarantee the quality, the binding connection is still the main form of horizontal bars connection.And in the current situation, the price is lower. But when the diameter of steel bar is thick, binding construction is difficult and easy to produce a wide crack. Therefore ,there are clear limits to its diameter. 


\section{Welding connection}

Welding connection (Fig.2) is directly transfer the force between the steel bar through the molten metal. If the welding quality is reliable, there is no defect of strength, stiffness, recovery performance, destructive characteristic and others. So it is the ideal way of connection. But there are many factors affecting the welding quality, such as voltage, climate, environment, construction conditions and operation level and ect.. So it is difficult to ensure the stable quality of the welding . In the case of ensuring quality, the welding connection may give priority to use .

\section{Mechanical connection}

Mechanical connection (Fig.3) is a new way of steel bar connection, which transfer the force through the sleeve between two steel bar. Main methods of mechanical connection : radial and axial extrusion bonding, taper thread connection, upsetting straight thread connection, rolling straight thread connection and so on. According to the present development situation, especially in the mechanical connection, steel stripping rib rolling straight thread is the main.

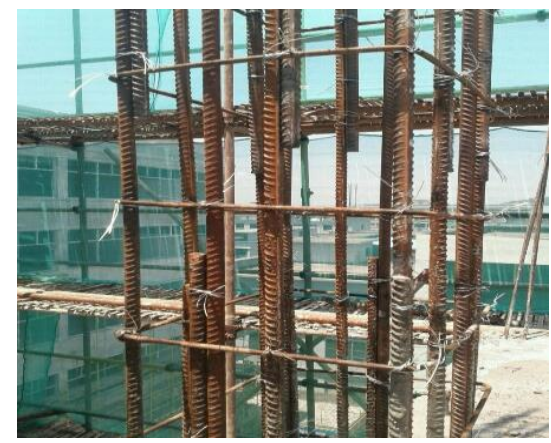

Fig.1 bundle connection

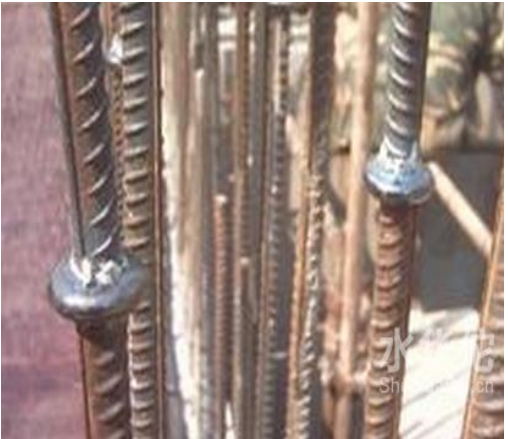

Fig. 2 welding connection

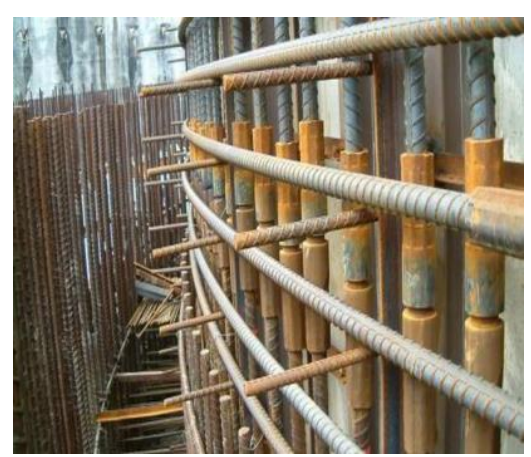

Fig.3 mechanical connection

\section{Vertical connection form of assembled shear wall structure}

According to the construction method, vertical connection form of assembled shear wall structure can be divided into two types: dry connection and wet connection. Dry connections includes post tension prestressed connection, bolt connection, Wall Shoes connection. The wet connection comprises constrained pulp anchor connection and sleeve grouting connection. Because of the smaller site of connections in assembly concrete structure, the dry connection is not easy to construct. In order to make the integrity and seismic performance of assembly concrete structure reach the purpose of the "basically equivalent to the cast-in-site concrete structure", the vertical steel bar connection of assembly concrete structure mainly use constrained pulp anchor connection and sleeve grouting connection. Mechanical connection and welded connections or sleeve grouting connection can be selected to use for the horizontal reinforcement connection according to actual situation.

\section{Constrained pulp anchor connection}

Constrained pulp anchor connection (Fig.4) is also known as indirect anchorage or indirect bonding. The steel bar is inserted into the reserved hole and the hole is take certain strengthen measures to improve the performance of steel bar connection. When the reinforcement in the channel was extended into the setting length through hole, the reinforce is transferred reliably by pouring micro expansion of cement-based grouting material into the reserved hole through the grouting hole and an exhaust hole.

\section{Sleeve connection}

As the present, in the assembly concrete structure, the main use of sleeve connection is mainly use to connect the steel bar. The following will focus on its summary.

(1)The classification and technical features of sleeve connection 
According to the form of structure, the sleeve is divided into full grouting sleeve (Fig.5) and the half grouting sleeve (Fig.6). When the steel bar is subjected to the action of the force, the force transmission way is as follows: the steel bar, the grouting material, the sleeve, the grouting material, and the other steel bar. Through the above ways to achieve the transmission of force between steel bars.

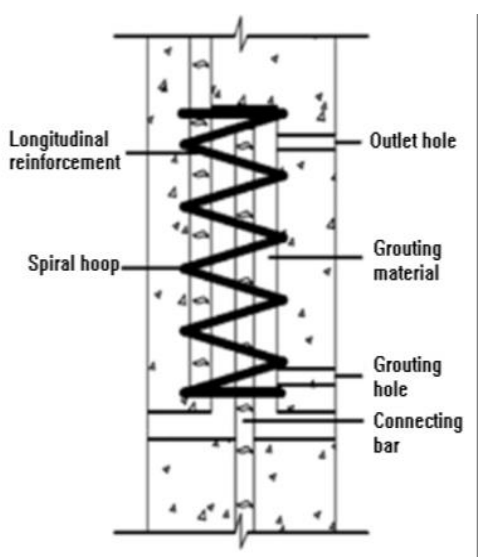

Fig. 4 the connection of steel bar anchor

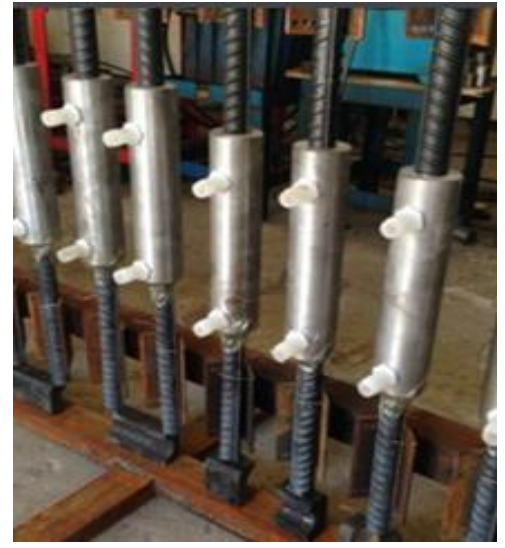

Fig. 5 full grouting sleeve

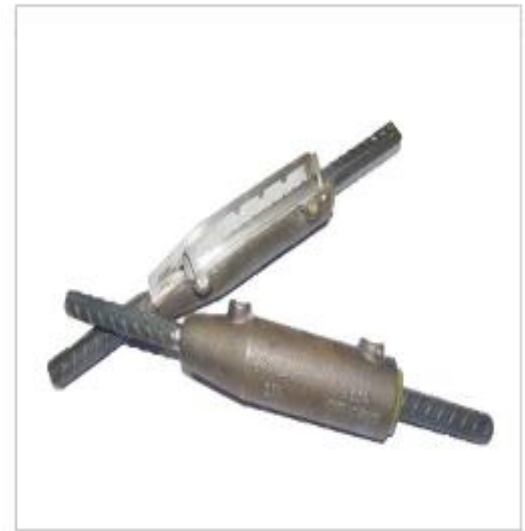

Fig. 6 half grouting sleeve

According to the manufacturing process, sleeve is divided into casting sleeve and mechanical processing sleeve [1]. Appearance of the sleeve should meet the following requirements: the surface of casting sleeve should not have the defects including slag, sand holes, porosity, cold insulation, crack and so on, which affect the quality of using performance. The surface of the mechanical processing sleeve is not allowed crack or other defects that affect the performance of the joint. The edge of the sleeve and the outer surface should be without sharp edges, burrs.

At present, in terms of material, the sleeve include ductile iron sleeve (fig. 7) and steel sleeve (fig. 8).

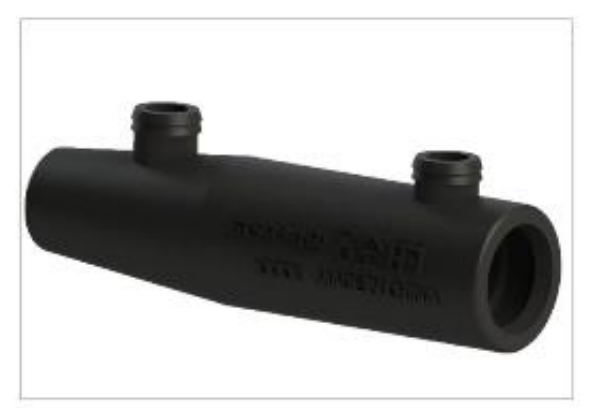

Fig. 7 "concrete" brand ductile iron sleeve

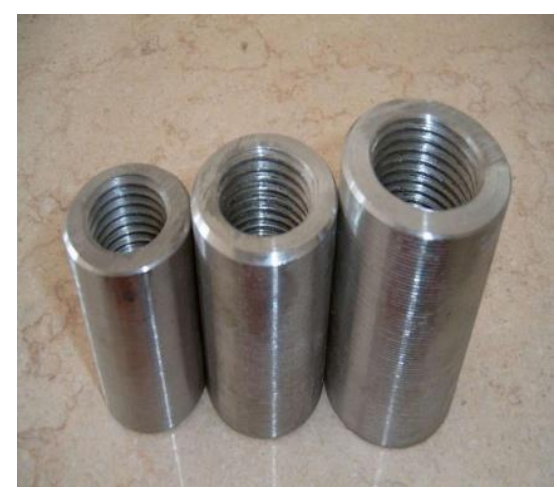

Fig. 8 structural steel sleeve

Sleeve by manufacturing process are prior to using ductile iron. And the sleeve by mechanical processing should use quality carbon structural steel, low alloy high strength structural steel, alloy structural steel or other type of steel which tested conform to the requirements.

Ductile iron should be in accordance with the provisions of GB/T 1348, its material performance still should be in accordance with the provisions of table 1 . 
Table 1 material properties of ductile iron sleeve

\begin{tabular}{|l|l|}
\hline Project & performance index \\
\hline Tensile strength $(\mathrm{MPa})$ & $\geq 600$ \\
\hline Extension rate $(\%)$ & $\geq 3 \%$ \\
\hline Percent of the rate of the ball $(\%)$ & $\geq 85 \%$ \\
\hline
\end{tabular}

High quality carbon steel, low alloy high strength structural steel, alloy structural steel processing and mechanical properties should be in accordance with GB / T 699, GB / T 8162, GB / T 1591 and GB / T 3077 and the provisions of Table 2.

Table 2 material properties of various types of steel sleeve

\begin{tabular}{|l|l|}
\hline Project & performance index \\
\hline Yield strength $(\mathrm{Mpa})$ & $\geqslant 355$ \\
\hline Tensile strength $(\mathrm{Mpa})$ & $\geqslant 600$ \\
\hline Extension rate $(\%)$ & $\geqslant 16$ \\
\hline
\end{tabular}

Ductile iron can effectively improve the mechanical properties of cast iron, especially the plasticity and toughness. And the strength is higher than carbon steel. To the advantage of the ductile iron: cast out of the complex shape, self lubricating effect, small friction coefficient and ect.. The price is slightly cheaper than steel. It is represented by "concrete" ductile iron sleeve which made of modern construction company in Shenzhen.

Compared with the existing grouting sleeve made of ductile iron, high quality carbon structural steel or alloy structural stee has better mechanical performance and the highly reliable quality .The advantages are obvious. But mechanical properties must be good only for steel.

The technical features of the sleeve are as follows: 1. It is suitable for the connection construction of steel bars in the reinforced concrete structures of various kinds of structures which are subjected to the bidirectional force of tension and compression. 2.Section material, energy saving, not subject to the restrictions of the composition and types of steel. 3.Can be fully connected. Does not occupy the time. The operation is convenient, fast and shorten the construction period.

(2) The development and research of the sleeve

At present, the sleeve grouting connection is widely used in the reinforcement connection of assembled monolithic structure. In the United States, the connection is already identified as a "wet" mechanical joint. In the early 1980s, Japan, New Zealand and other countries are widely used it in engineering practice.In the early 70's of last century, the United States structural engineer A.Yee DR.Alfred invented the reinforced connection with grouting sleeve and carried out a practical engineering application. In the 1973 Japan Nisso Master Bu ilders (NMB) introduced the grouting connecting sleeve for production research. They improved the sleeve shape and internal structure of sleeve. Now this technology in Japan has tended to be mature. In 1986, X type grouting connection sleeve was successfully developed and widely used in North American and Japanese steel connections in prefabricated building. After the grouting sleeve technology was introduced into China, the researchers of engineering and technology in China were studied and improved and innovation on the basis of this kind of sleeve. Such as the domestic JM cement grouting straight thread joint was inventded by Zheng Yongfeng[2] in Southeast University.

Qian Jiaru[3], who made a series of experimental study on the seismic performance of the vertical steel in the form of sleeve grouting connection and the reliability of grout sleeve connection. The test results show that the vertical steel bar can effectively transfer the stress of the steel bar, and the failure mode is the same as the cast-in-site specimen. $\mathrm{Xu}$ Wei[4], who study on the characteristics, key construction points and the matters needing attention of steel sleeve grouting connections in prefabricated concrete structure. Construction results show that economic effect is good. Qin Heng [5], through on analysis of the construction process and material characteristics of 
connection, clarified the key factors which influenced the quality of the connection. And they puts forward some more complete technical measures to ensure the quality of construction. Engineering practice shows that the measures are effective. And the seismic behavior of the assembled shear wall is studied by Professor Khaled[6] in Canada. The seismic behavior of the joints at the bottom of the assembled shear wall is simulated by using different connection forms.

(3)The problems existing in the application of the sleeve

Due to the diameter of sleeve greater than steel bar, we need to increase the thickness of concrete protective layer. The cost of sleeve connection is higher, especially steel threading cost. The construction process is more complicated because of the need of grouting in the sleeve. We can't see the case of the cylinder when grouting, there may be likely to perfusion dissatisfaction.

\section{Conclusion Outlook}

Above the current connection method of steel bar is reviewed, it can be seen that :

(1)The connection way of steel bar is more. Among the technology of steel bar connection, steel sleeve grouting connection can effectively transfer the stress of steel bar and reduce the workload of welding or bonding in construction site. It also can better guarantee the quality of vertical bar connection. But there have problems including high cost, perfusion dissatisfaction ,the construction quality by the effects of operating personnel and so on.

(2) From the angle of building structure and construction process, while the vertical bar connection technology in the continuous research, but it is difficult to obtain the breakthrough progress. Therefore, it is urgent to research a connection material with low cost and convenient construction from the angle of material.

(3) With the development of research and the increasing demand of housing quantity, prefabricated assembly shear wall structure is a new opportunity for the development of construction industry. As one of the key technologies of the steel bar connection, its theoretical research should go ahead.So the research on the connection material is broad, and the prospect is wide.

\section{Acknowledgement}

This work is financially supported by the General project of Shenyang Jianzhu university(2015147).

\section{References:}

[1] Industry standard of the people's Republic of China. Grouting sleeve for JGT398-2012 steel bar connection [S]. Beijing: China Building Industry Press, 2013

[2] Yong-Feng ZHENG, Zheng-Xing GUO, Zhi-Cheng SUN: Experimental Study on the Behavior of Grouted Deformed Pipe Splice [J]. Construction technology Vol.22 (2014), p.40-44

[3] Jia-Ru QIAN, Yuan-Yuan PENG, Jing-Ming ZHANG and ect.: Tests on seismic behavior of pre-cast shear walls with vertical reinforcements spliced by grout sleeves [J]. Building structure Vol.2( 2011), p.1-6

[4] Wei XU, Peng ZHANG, Fang-Yong WEI, Xiao-Hui HU: Grout Sleeve Splicing Application in Precast Concrete Structures [J]. Construction technology Vol.43(2014), p.567 - 569

[5] Heng QIN, Guan-Long QIAN. The Construction Quality Control Measures of Coupler Grouting Splice for Reinforcement [J].Construction technology Vol.42( 2013), p.113-117

[6] KhaledA . Soudki , SamiHRizkalla . Horizontal Connection for Precast Concrete Shear Walls Subjected to Cyclic Deformations . PCIJourna 1, vol.4(1995 ), p. 78 - 96 